\title{
EFFECTS OF NITROGEN PHOTOABSORPTION CROSS SECTION RESOLUTION ON MINOR SPECIES VERTICAL PROFILES IN TITAN'S UPPER ATMOSPHERE
}

\author{
A. Luspay-Kuti ${ }^{1}$, K. E. Mandt ${ }^{1}$, S. Plessis ${ }^{2}$, and T. K. Greathouse ${ }^{1}$ \\ ${ }^{1}$ Space Science \& Engineering Division, Southwest Research Institute, 6220 Culebra Road, San Antonio, TX 78238, USA; aluspaykuti@swri.edu \\ 2 ICES, The University of Texas at Austin, 201 East 24th Street, Austin, TX 78712, USA \\ Received 2015 January 21; accepted 2015 February 11; published 2015 March 2
}

\begin{abstract}
The significant variations in both measured and modeled densities of minor species in Titan's atmosphere call for the evaluation of possible influencing factors in photochemical modeling. The effect of nitrogen photoabsorption cross section selection on the modeled vertical profiles of minor species is analyzed here, with particular focus on $\mathrm{C}_{2} \mathrm{H}_{6}$ and $\mathrm{HCN}$. Our results show a clear impact of cross sections used on all neutral and ion species studied. Affected species include neutrals and ions that are not primary photochemical products, including species that do not even contain nitrogen. The results indicate that photochemical models that employ low-resolution cross sections may significantly miscalculate the vertical profiles of minor species. Such differences are expected to have important implications for Titan's overall atmospheric structure and chemistry.
\end{abstract}

Key words: atmospheric effects - methods: numerical - planets and satellites: atmospheres - planets and satellites: individual (Titan)

\section{INTRODUCTION}

Titan with its unique, dense atmosphere has been the focus of scientific interest for seven decades now, starting with the first quantitative spectroscopic observations by Kuiper (1944). Our knowledge of Saturn's largest moon has since been shaped significantly by direct observations with the Voyager spacecraft and by the invaluable data the Cassini-Huygens mission has been providing for over 10 years. Titan's rich, complex organic chemistry begins in the upper atmosphere with the photolytic destruction of two molecules: $\mathrm{N}_{2}$ and $\mathrm{CH}_{4}$. The multitude of reactions among the produced neutrals, ions, and background gas that follows leads to the formation of various heavier hydrocarbons, nitriles, and, ultimately, Titan's characteristic orange haze. The details of neutral, ion-molecule, and electron chemistry have key implications for the structure and evolution of Titan's atmosphere, and essentially influence its surfaceatmosphere interactions.

Of high importance in this scheme is the production of the hydrocarbon species ethane, $\mathrm{C}_{2} \mathrm{H}_{6}$, and the nitrile hydrogen cyanide, HCN. Ethane formation is an important sink for methane photolysis, with $\sim 40 \%$ of the total methane loss attributed to ethane production (Wilson \& Atreya 2009). The $\mathrm{C}_{2} \mathrm{H}_{6}$ created continues, in part, to participate in further reactions forming benzene, an important precursor to polycyclic aromatic hydrocarbon (PAH) formation and, in part, condenses onto the surface, where the pressure and temperature conditions allow it to exist in its liquid phase. Of the nitriles, production and loss of $\mathrm{HCN}$ is of particular interest. $\mathrm{HCN}$ is the first step in incorporating nitrogen into tholins; hence, it is highly relevant to potential amino acid formation (Khare et al. 1986). Furthermore, HCN plays an important role in producing the major ion species in Titan's ionosphere through the reaction $\mathrm{C}_{2} \mathrm{H}_{5}^{+}+\mathrm{HCN} \rightarrow \mathrm{HCNH}^{+}+\mathrm{C}_{2} \mathrm{H}_{4}$. It is also the main coolant in the upper atmosphere (Yelle 1991; Bell et al. 2010).

Both species have been measured by various spacecraft instruments on board the Voyager and Cassini, as well as through ground-based observations. Stratospheric measurements of $\mathrm{C}_{2} \mathrm{H}_{6}$ abundance taken from different sources (e.g.,
Coustenis and Bézard 1995; Livengood et al. 2002, 2006; Coustenis et al. 2003, 2010; Kostiuk et al. 2005; Vinatier et al. $2007,2009)$ are generally in agreement within the error bars (Figure 1, right). The same is true for globally averaged $\mathrm{C}_{2} \mathrm{H}_{6}$ mixing ratios obtained from Cassini's Ion and Neutral Mass Spectrometer (INMS) data (Cui et al. 2009; Magee et al. 2009). Mixing ratios from the Cassini Ultraviolet Imaging Spectrograph are significantly higher at $1000 \mathrm{~km}$ (Shemansky et al. 2005). In a later analysis of UVIS data, only an upper limit could be derived for $\mathrm{C}_{2} \mathrm{H}_{6}$ between 700 and $750 \mathrm{~km}$ (Koskinen et al. 2011; Figure 1, right). The distribution of $\mathrm{C}_{2} \mathrm{H}_{6}$ in the stratosphere as a function of latitude shows slight variability between the two hemispheres. A factor of $\sim 2$ enhancement was measured at the northern high latitudes for the northern winter season (Coustenis et al. 2010; Figure 1, right).

Unlike $\mathrm{C}_{2} \mathrm{H}_{6}$, measurements of $\mathrm{HCN}$ demonstrate high variability, with values differing by an order of magnitude at high altitudes and two orders of magnitude at mid-altitudes (Tanguy et al. 1990; Hidayat et al. 2002, 1997; Gurwell 2004; Vervack et al. 2004; Kim et al. 2005; Shemansky et al. 2005; Coustenis et al. 2010; Adriani et al. 2011; Koskinen et al. 2011; Figure 1, left). Furthermore, stratospheric CIRS data show a latitudinal variation in $\mathrm{HCN}$ abundance, spanning almost two orders of magnitude of variance between the poles (Coustenis et al. 2010). The significant difference between measurements taken on different occasions indicates that $\mathrm{HCN}$ may exhibit strong variations on diurnal and/or seasonal timescales; its abundance may be highly sensitive to photon flux changes over the solar cycle. Recent analysis of CIRS data suggests seasonal changes in the latitudinal HCN distribution (Coustenis et al. 2014), supporting the former idea.

In addition, the high variability that exists among predicted abundances of both $\mathrm{HCN}$ and $\mathrm{C}_{2} \mathrm{H}_{6}$ from photochemical models poses another issue. Model predictions of HCN mixing ratios vary by up to two orders of magnitude in the upper atmosphere, and $\mathrm{C}_{2} \mathrm{H}_{6}$ abundances show variations of up to an order of magnitude (Yung et al. 1984; Toublanc et al. 1995; Lara et al. 1996; Vuitton et al. 2007; Carrasco et al. 2008; de la 

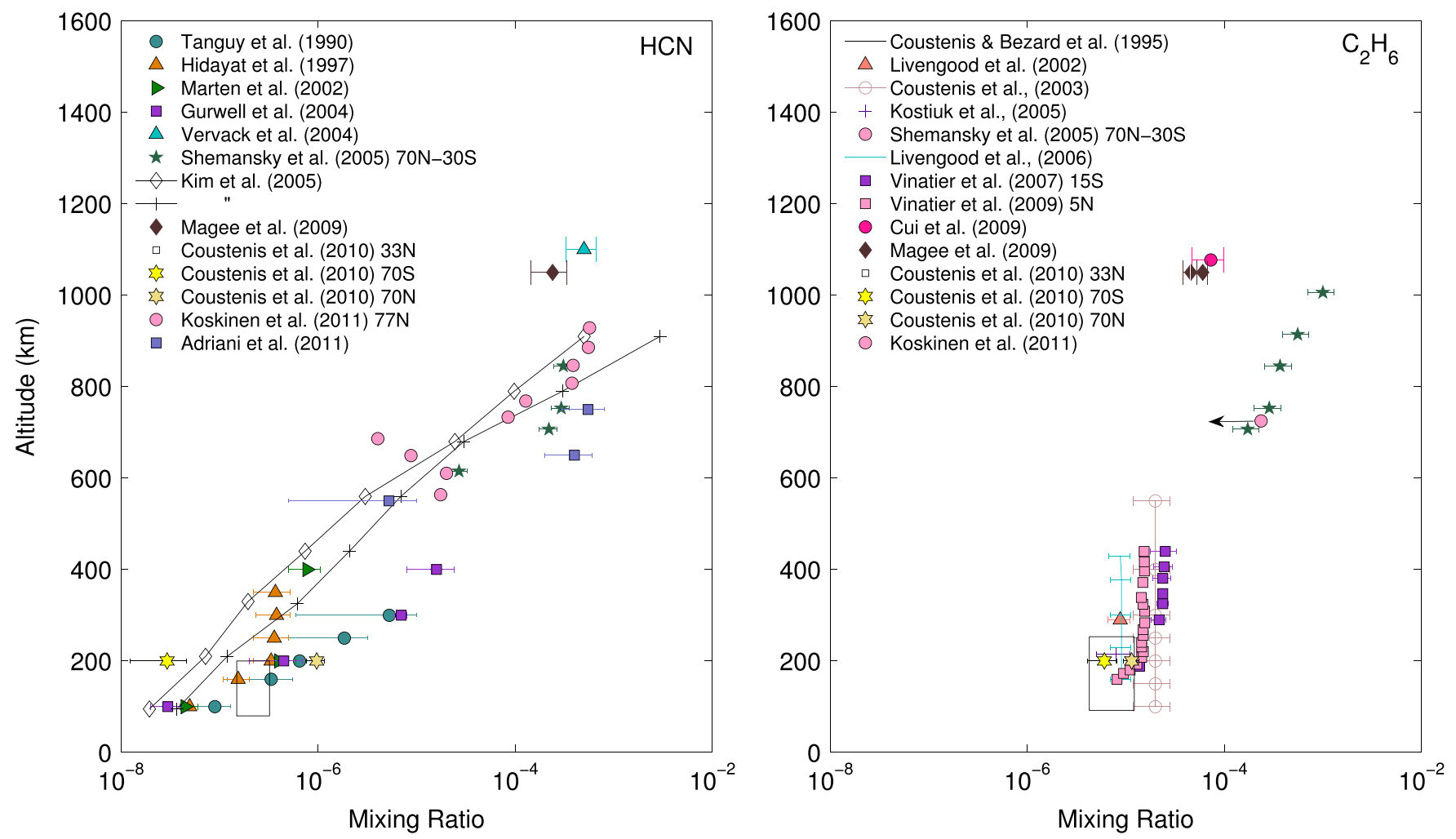

Figure 1. Abundance of $\mathrm{HCN}$ and $\mathrm{C}_{2} \mathrm{H}_{6}$ as a function of altitude from spacecraft and ground-based measurements. Data points are global average values unless the latitude is noted. The arrow indicates upper limit mixing ratios.

Haye et al. 2008; Lavvas et al. 2008; Krasnopolsky 2009). This suggests that photochemical model results are very sensitive to the initial assumptions made about model input parameters and/ or to the chemistry employed. Isolating which of these parameters is the main cause of the observed discrepancies is a challenging task and requires a thorough evaluation of all the possible influencing factors.

Photoabsorption cross sections of the absorbing molecules are an important input parameter in all photochemical models. Cross sections for the main atmospheric constituent, $\mathrm{N}_{2}$, and its heavy isotope ${ }^{14} \mathrm{~N}^{15} \mathrm{~N}$ have been shown to be highly structured as a function of wavelength. Liang et al. (2007) demonstrated that this structural complexity has a clear impact on Titan's nitrogen chemistry, leading to a higher modeled relative production rate of $\mathrm{HC}^{15} \mathrm{~N}$ with the use of high-resolution (HR) cross sections than with the use of low-resolution (LR) cross sections. Furthermore, they showed that the photolytic fractionation between ${ }^{14} \mathrm{~N}_{2}$ and ${ }^{14} \mathrm{~N}^{15} \mathrm{~N}$ explains the measured difference in the ${ }^{14} \mathrm{~N} /{ }^{15} \mathrm{~N}$ ratio between $\mathrm{N}_{2}$ and $\mathrm{HCN}$ (Vinatier et al. 2007; Niemann et al. 2010). The cross sections of $\mathrm{CH}_{4}$ are nearly flat over the same wavelength range where the cross sections of nitrogen are highly structured. Nevertheless, the work of Lavvas et al. (2011) revealed that not only is nitrogen chemistry impacted by cross-section resolution, but it is also highly relevant to the photolytic loss of $\mathrm{CH}_{4}$ as well. Photons that are not absorbed by $\mathrm{N}_{2}$ at higher altitudes can be absorbed by $\mathrm{CH}_{4}$, leading to higher $\mathrm{CH}_{4}$ and lower $\mathrm{N}_{2}$ destruction rates compared to when LR cross sections are used. Based on their results, Lavvas et al. (2011) predicted that the use of HR cross sections is necessary for accurate representation of the primary photodissociation and photoionization products-a prediction confirmed by Mandt et al. (2012), as demonstrated for the primary ion $\mathrm{CH}_{4}^{+}$through model-data comparisons.

These results from the limited number of studies available may have important implications for higher-order photochemistry products. Thus, investigating the possible influence on important minor species has high value. We evaluate the effect of using $\mathrm{HR} \mathrm{N}_{2}$ photoabsorption cross sections on the production rate and abundance profiles of $\mathrm{C}_{2} \mathrm{H}_{6}$ and $\mathrm{HCN}$ in Titan's upper atmosphere. Other minor neutral and ion species that participate in the production of $\mathrm{C}_{2} \mathrm{H}_{6}$ and $\mathrm{HCN}$ are also considered. Our results show that the spectral resolution of the cross sections used has a non-negligible effect on the resulting minor vertical profiles.

\section{PHOTOCHEMICAL MODELING}

We used the coupled ion-neutral-thermal model of de la Haye et al. (2008), as updated by Mandt et al. (2012; INT12). This photochemical model was developed specifically for Cassini INMS data comparison. It was first validated by data acquired from the first two flybys $\left(\mathrm{T}_{A}\right.$ and $\mathrm{T}_{5}$; de la Haye et al. 2008) and later with data from two dayside flybys (T40 and T48; Mandt et al. 2012). A detailed description of the model can be found in the aforementioned references; therefore, only details specific to this study will be described here.

Production rates, as well as mixing ratio profiles are calculated as a function of altitude by running INT12 in an LR and an HR mode. The LR mode employs temperaturedependent $\mathrm{N}_{2}$ and ${ }^{14} \mathrm{~N}^{15} \mathrm{~N}$ photoabsorption cross sections with a resolution of $\sim 50 \AA$ (Fennelly \& Torr 1992) and calculates the solar flux using the EUV flux model for aeronomic calculations (EUVAC; Richards et al. 1994). The HR mode uses temperature-dependent cross sections (Liang et al. 2007) 


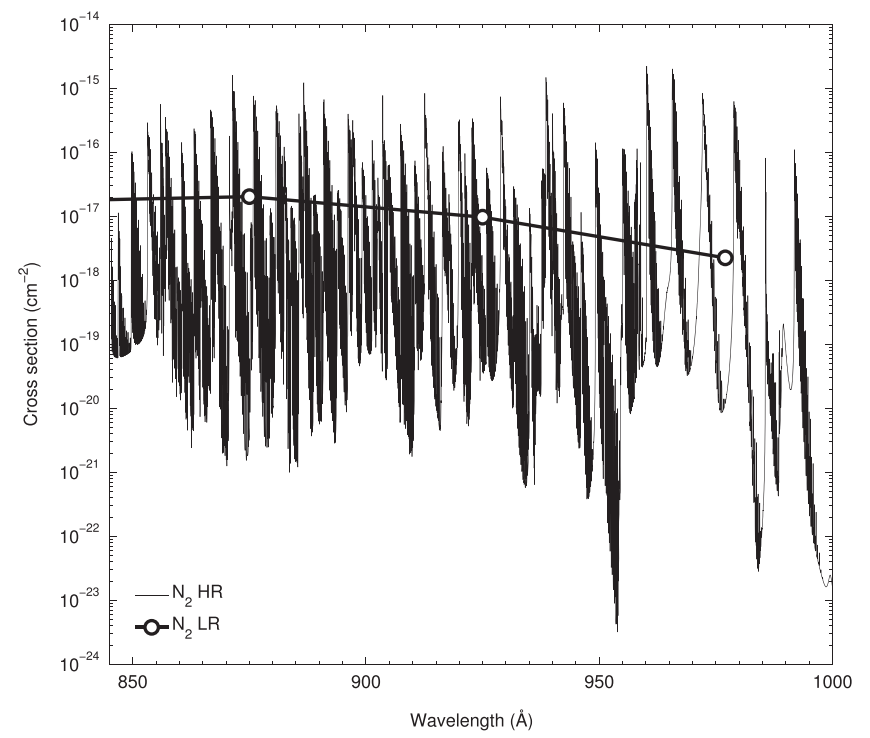

Figure 2. High-resolution (HR) and low-resolution (LR) nitrogen cross sections as a function of wavelength in the INT12 model.

averaged into $0.1 \AA$ bins and suitable solar flux values from the high-resolution EUVAC model (HEUVAC; Richards et al. 2006) between the wavelength range 845 and $1000 \AA$. Figure 2 illustrates the drastic difference between LR and HR cross sections as a function of wavelength in the model. An average radio flux of $F_{\mathrm{avg}}^{10.7 \mathrm{~cm}}=70$ s.f.u. is employed, which corresponds to solar minimum conditions. $\mathrm{Ly} \alpha \mathrm{CH}_{4}$ photodissociation branching ratios used in the model are updated to those reported by Gans et al. (2013). Because there is a lack of detailed studies in the 1300-1400 ̊ wavelength range, the Ly $\alpha$ branching ratios are extrapolated to the non-Ly $\alpha$ wavelengths. This is done in order to avoid overproduction of the major saturated hydrocarbons, as would result from attributing $100 \%$ of the $\mathrm{CH}_{4}$ photodissociation to $\mathrm{CH}_{3}$ production, as recommended by Gans et al. (2013). Dissociation and ionization by electron impact is not considered in either model configuration (LR and HR).

We adopt the eddy diffusion profile of Yelle et al. (2008), which corresponds to a constant mixing rate of $3.5 \times 10^{7} \mathrm{~m}^{2} \mathrm{~s}^{-1}$ in the altitude range studied in this work $(600-1600 \mathrm{~km})$. Modeled $\mathrm{C}_{2} \mathrm{H}_{6}, \mathrm{HCN}$, and $\mathrm{HC}^{15} \mathrm{~N}$ production rates and abundances are calculated by the model at the lower boundary of $600 \mathrm{~km}$. Other neutrals are kept fixed at $600 \mathrm{~km}$ based on Cassini CIRS and Gas Chromatograph and Mass Spectrometer (GCMS) measurements at lower altitudes. Production rates and vertical profiles are modeled for global average conditions $\left(60^{\circ}\right.$ solar zenith angle; solar flux multiplied by 0.5 ).

\section{RELATIVE ABUNDANCE AND PRODUCTION RATES}

Comparing the high- to low-resolution simulations allows us to determine the relative importance of cross-section selection on the abundance and production rate profiles. For both $\mathrm{C}_{2} \mathrm{H}_{6}$ and $\mathrm{HCN}$, the modeled abundances are higher with the use of $\mathrm{HR}$ cross sections at all altitudes (Figure 3 ). Both $\mathrm{HCN}$ and $\mathrm{C}_{2} \mathrm{H}_{6}$ exhibit a maximum increase with $\mathrm{HR}$ above $1200 \mathrm{~km}$. The $\mathrm{C}_{2} \mathrm{H}_{6}$ mixing ratio increases by $\sim 20 \%$ compared to the LR mixing ratio above $1200 \mathrm{~km}$. The maximum increase in $\mathrm{HCN}$ with the use of HR cross sections is slightly more pronounced. HCN abundance increases by about $35 \%$ above $1200 \mathrm{~km}$. At the lower boundary, HCN abundance increased by $28 \%$ with the HR cross sections, as illustrated by the non-unity value of the HR/LR ratio at $600 \mathrm{~km}$ in Figure 3. At the same time, the lower boundary of $\mathrm{C}_{2} \mathrm{H}_{6}$ is barely influenced by the crosssection selection ( $\sim 5 \%$ increase with $\mathrm{HR})$.

HR to LR production ratios are shown in Figures 4 and 5 in order to evaluate how much of the increase in abundance can be attributed to production from various types of chemistry. Between 600 and $1000 \mathrm{~km}, \mathrm{C}_{2} \mathrm{H}_{6}$ is essentially entirely produced though termolecular reactions (Figure 4(a)). Primarily, these reactions involve two $\mathrm{CH}_{3}$ molecules and a background gas molecule that acts as catalyst (Wilson \& Atreya 2004, 2009; Lavvas et al. 2008; Krasnopolsky 2009). This is clearly demonstrated in Figure 4(b) by the overlapping production (left) and abundance (right) ratio profiles of $\mathrm{C}_{2} \mathrm{H}_{6}$ and $\mathrm{CH}_{3} \cdot \mathrm{C}_{2} \mathrm{H}_{6}$ production by termolecular chemistry is most sensitive to cross section resolution between 700 and $1000 \mathrm{~km}$. In this altitude regime, termolecular production rates increase by $30 \%$ compared to when LR cross sections are used. Between $1000 \mathrm{~km}$ and $1200 \mathrm{~km}$, termolecular reactions still dominate the $\mathrm{C}_{2} \mathrm{H}_{6}$ production, with decreasing importance. At the same time, the role of neutral (bimolecular) chemistry continuously increases from the initial $\sim 2 \%$ of total production at lower altitudes (Figure 4(a), right). This effect becomes especially apparent at $1050 \mathrm{~km}$, when the $\mathrm{C}_{2} \mathrm{H}_{6}$ profile is visibly forced toward larger production ratios. Neutral chemistry producing $\mathrm{C}_{2} \mathrm{H}_{6}$ is most affected by the spectral resolution of the assumed cross sections near this altitude. The increase with HR cross sections in the relative importance of neutral chemistry $(\sim 1100 \mathrm{~km}$ in Figure $4(\mathrm{a})$, left $)$ is comparable in magnitude to that of $\mathrm{C}_{2} \mathrm{H}_{5}$ (Figure 4(b)). This indicates that the most relevant $\mathrm{C}_{2} \mathrm{H}_{6}$ producing bimolecular neutral reactions involve the minor neutral $\mathrm{C}_{2} \mathrm{H}_{5}$ (Figure 4(b)). While other trace neutrals, such as ${ }^{15} \mathrm{NH}$ may exhibit significant increase in production with the use of $\mathrm{HR}$ cross sections, there is little influence on the overall $\mathrm{C}_{2} \mathrm{H}_{6}$ trend (Figure $4(\mathrm{~b})$ ) due to their low atmospheric abundance.

Neutral chemistry takes over at $1180 \mathrm{~km}$ (HR) or $1220 \mathrm{~km}$ (LR) depending on the cross sections used. The largest difference between LR and $\mathrm{HR} \mathrm{C}_{2} \mathrm{H}_{6}$ production rates occurs near these altitudes. Above $\sim 1200 \mathrm{~km}$, bimolecular neutral chemistry is the primary process producing $\mathrm{C}_{2} \mathrm{H}_{6}$. The importance of neutral chemistry increases with altitude, constituting nearly $100 \%$ of all $\mathrm{C}_{2} \mathrm{H}_{6}$ production at $1500 \mathrm{~km}$ and above. While there is increased contribution from ionmolecule chemistry at $1200 \mathrm{~km}$, it only accounts for less than $6 \%$ of the total $\mathrm{C}_{2} \mathrm{H}_{6}$ production.

At the same time, $\mathrm{HCN}$ production is entirely dominated by neutral chemistry below $1000 \mathrm{~km}$ (Figure 5(a)). Total HCN production rates increase by as much as $70 \%$ at $900 \mathrm{~km}$, primarily due to the effect of cross-section selection on $\mathrm{H}_{2} \mathrm{CN}$ (Figure 5(b)). Above $1000 \mathrm{~km}$, electron recombination becomes more important with increasing altitude, but cannot exceed the contribution of neutral chemistry. A combination of neutral and electron recombination reactions thus determine the $\mathrm{HCN}$ production ratio profile above $1000 \mathrm{~km}$ (Figure 5(a)). $\mathrm{HCN}$ production through ion-molecule chemistry is marginal compared to neutral chemistry throughout the entire column. Thus, the total production ratio profile of $\mathrm{HCN}$ is not affected by ion-molecule chemistry, regardless of the sensitivity of ionmolecule reactions to the spectral resolution of the cross sections. 


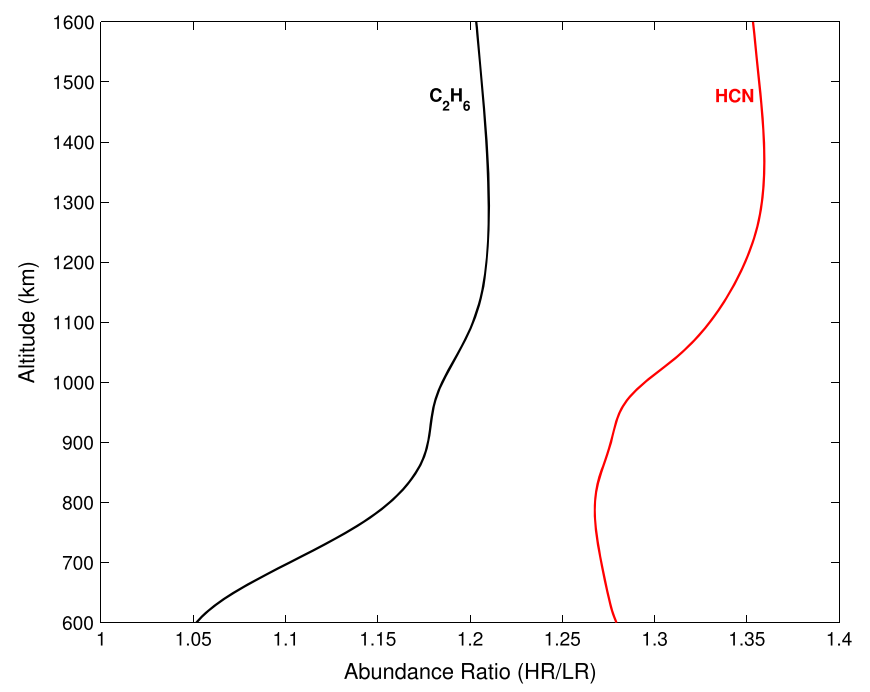

Figure 3. $\mathrm{C}_{2} \mathrm{H}_{6}$ and $\mathrm{HCN}$ mixing ratios from simulations using high-resolution cross sections (HR) relative to simulations using low-resolution cross sections (LR). In the case of both species, higher abundances are obtained with the use of high-resolution $\mathrm{N}_{2}$ cross sections.

In the case of both $\mathrm{C}_{2} \mathrm{H}_{6}$ and $\mathrm{HCN}$, ion-molecule chemistry decreases with the use of $\mathrm{HR}$ cross sections at higher altitudes $(>900 \mathrm{~km})$. This results in the opposite trend compared to the other types of chemistry contributing to their production. The decrease is due to reduced ion abundances with better resolution cross sections, as illustrated in Figures 4(b) and 5(b). Ion densities decrease when HR cross sections are employed because more ionizing radiation can penetrate to greater depths in the atmosphere. This lowers the EUV radiation available for photoionization at higher altitudes, thus producing less ions compared to when LR cross sections are used. Ion-molecule chemistry is significantly less important in the production of $\mathrm{C}_{2} \mathrm{H}_{6}$ and $\mathrm{HCN}$ than other types of chemistry. However, the reduced ion density of $\mathrm{HCNH}^{+}$with the use of HR cross sections affects the electron recombination formation of $\mathrm{HCN}$ in a similar way. With less available ions at higher altitudes, less electron recombination can take place to produce $\mathrm{HCN}$.

The modeled rate of production of $\mathrm{HCN}$ is highly sensitive to the spectral resolution of the nitrogen cross sections between $800-900 \mathrm{~km}$. However, its abundance ratio profile does not demonstrate changes comparable in magnitude to that of the production rate ratio (Figure 5(b)). Loss rates at these altitudes are not sufficient to account for this difference. At the same time, the abundance ratio profile of $\mathrm{C}_{2} \mathrm{H}_{6}$ and various other neutrals $\left(\mathrm{C}_{2} \mathrm{H}_{5}, \mathrm{C}_{3} \mathrm{H}_{8}, \mathrm{H}_{2} \mathrm{CN}\right.$, etc. $)$ can be explained by the relative importance of production to loss rates at a given altitude. This indicates that the HCN abundance is less sensitive to production and loss than the $\mathrm{C}_{2} \mathrm{H}_{6}$ abundance. Indeed, there is a sufficient amount of $\mathrm{HCN}$ present compared to rates of production and loss in the upper atmosphere that its altitude profile does not change significantly. Furthermore, the time constant for $\mathrm{HCN}$ is nearly twice as high as the time constant of $\mathrm{C}_{2} \mathrm{H}_{6}$ at $800-900 \mathrm{~km}$. The higher abundance and longer life time of $\mathrm{HCN}$ compared to $\mathrm{C}_{2} \mathrm{H}_{6}$ makes $\mathrm{HCN}$ less sensitive to being perturbed by production and loss. Therefore, $\mathrm{HCN}$ is more stable in photochemical models than $\mathrm{C}_{2} \mathrm{H}_{6}$.
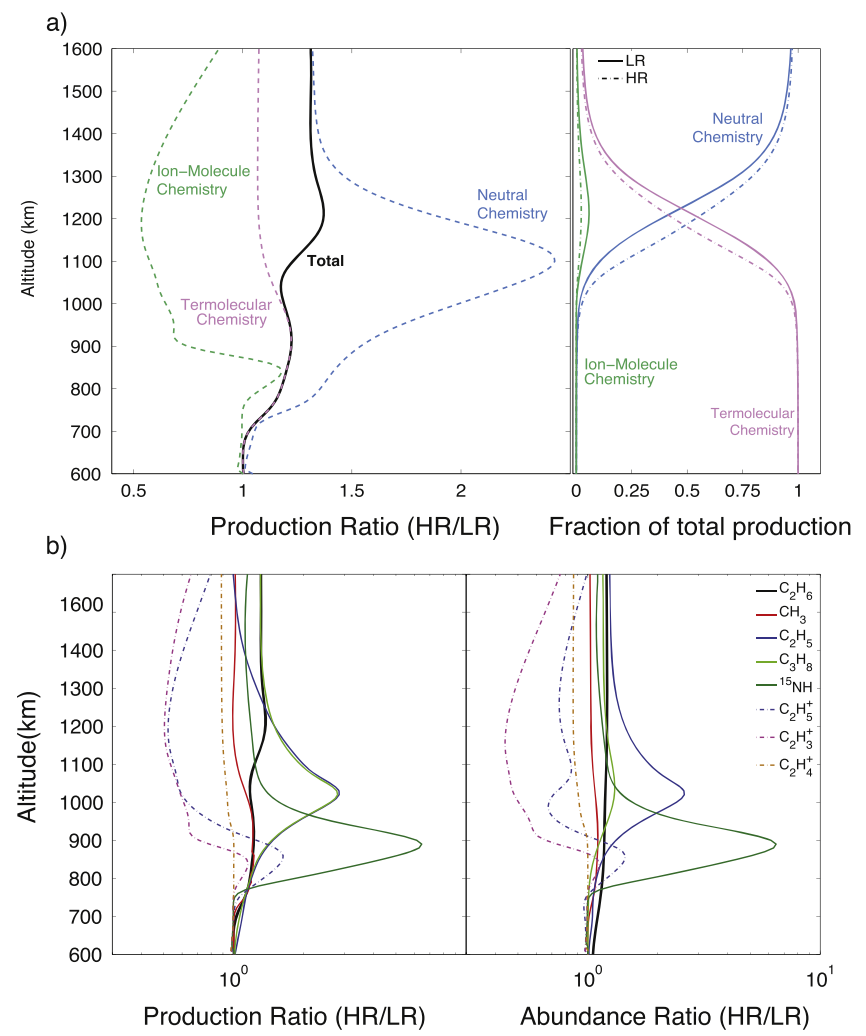

Figure 4. (a) Left: production rate ratio for $\mathrm{C}_{2} \mathrm{H}_{6}$ from various types of chemistry using high-resolution cross sections relative to low-resolution cross sections (HR/LR). Right: altitude-dependent fraction of total production from different types of chemistry. (b) Left: HR/LR total production ratios for the main species contributing to $\mathrm{C}_{2} \mathrm{H}_{6}$ production. Right: high-to-low-resolution abundance ratios. Note that values for these plots are on a logarithmic scale.

\subsection{Discussion and Conclusions}

A clear effect of nitrogen photoabsorption cross-section resolution on minor neutral production rates and abundances is apparent, with varying sensitivity from one species to the next. Minor neutrals that do not even bear nitrogen are also affected. Production rates of the studied neutrals vary from a factor of 1.2 up to 6.5 depending on $\mathrm{N}_{2}$ cross-section selection. The mixing ratios of $\mathrm{C}_{2} \mathrm{H}_{6}$ and $\mathrm{HCN}$ showed a maximum increase of $20 \%$ and $35 \%$ respectively, while their modeled production rates increased by as much as 30\%-70\% when HR cross sections were used. This suggests that not only are the altitudedependent photodissociation rates of the parent molecules $\mathrm{N}_{2}$ and $\mathrm{CH}_{4}$ misrepresented by models that use LR cross sections, as noted previously by Lavvas et al. (2011) and Mandt et al. (2012), but so are the abundances of minor neutrals. These models likely underestimate the abundances of $\mathrm{C}_{2} \mathrm{H}_{6}, \mathrm{HCN}$, and most neutral species, while the ion densities are overestimated.

The total production rates of $\mathrm{C}_{2} \mathrm{H}_{6}$ and $\mathrm{HCN}$ integrated through the column change marginally with the use of $\mathrm{HR}$ nitrogen cross sections (factor of $1.14\left(\mathrm{C}_{2} \mathrm{H}_{6}\right)$ and $1.02(\mathrm{HCN})$ increase). The total column-integrated production of $\mathrm{C}_{2} \mathrm{H}_{6}$ and $\mathrm{HCN}$ are essentially governed by termolecular and bimolecular neutral chemistry, respectively, with negligible contribution from other types of chemistry (Table 1). However, production rates and abundances show significant variations as a function of altitude. This is due to the sensitivity of the various types of chemistry by which these neutrals are produced, as illustrated 
a)

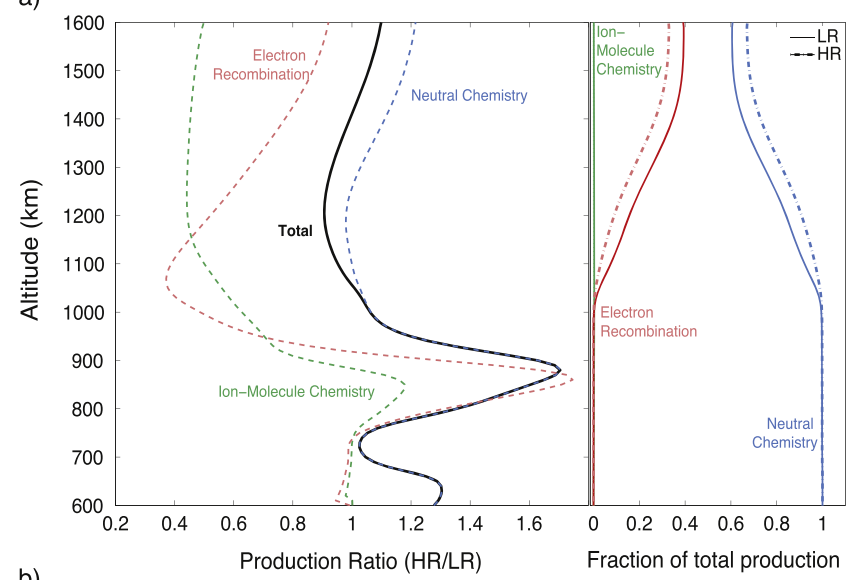

b)

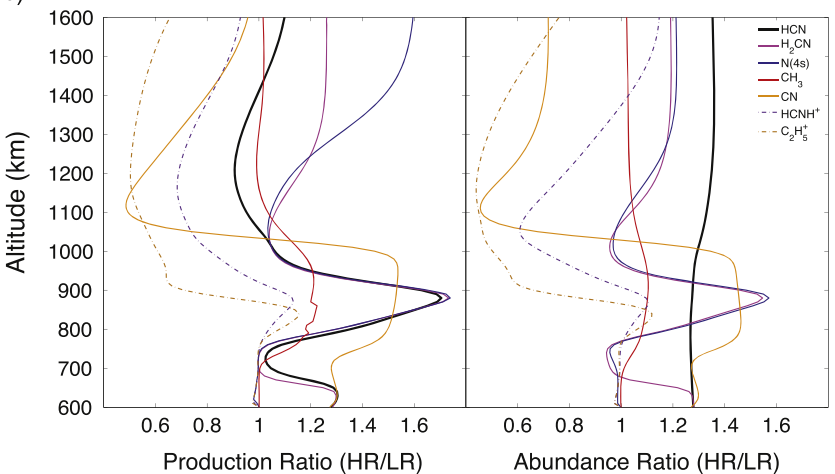

Figure 5. (a) Left: relative $\mathrm{HCN}$ production rates as a function of altitude for various types of chemistry. Right: altitude-dependent fraction of total production from different types of chemistry. (b) Left: high-to-low-resolution total production ratios for the main species contributing to $\mathrm{HCN}$ production. Right: high-to-low-resolution abundance ratios.

Table 1

Modeled Column-integrated Production in Percentage from Various Types of Chemistry

\begin{tabular}{llcr}
\hline \hline & & \multicolumn{2}{c}{$\begin{array}{c}\text { Percent of Total } \\
\text { Production }\end{array}$} \\
\cline { 3 - 4 } & & LR & HR \\
\hline \multirow{2}{*}{$\mathrm{C}_{2} \mathrm{H}_{6}$} & Neutral Chemistry & $0.16 \%$ & $0.21 \%$ \\
& Termolecular Chemistry & $99.84 \%$ & $99.77 \%$ \\
& Ion-molecule Chemistry & $0.004 \%$ & $0.002 \%$ \\
\hline \multirow{3}{*}{$\mathrm{HCN}$} & Neutral Chemistry & $93.19 \%$ & $96.70 \%$ \\
& Electron Recombination & $6.51 \%$ & $3.13 \%$ \\
& Ion-molecule Chemistry & $0.31 \%$ & $0.17 \%$ \\
\hline
\end{tabular}

Note. LR and HR refer to simulations using low-resolution and high-resolution cross sections, respectively.

in Figures 4(a) and 5(a). There is a clear change of chemical regime with altitude at $1000 \mathrm{~km}$ for both $\mathrm{C}_{2} \mathrm{H}_{6}$ and $\mathrm{HCN}$. Above this altitude, the types of chemistry otherwise insignificant for the overall column abundance of minor neutrals become more important with altitude, and may even dominate the production.

Such differences have significant implications for Titan's upper-and possibly also lower-atmospheric chemistry. First, an increase in $\mathrm{HCN}$ density due to cross-section selection would impact the energy balance of the thermosphere via increased cooling rates. It may also change the rate at which nitrogen is incorporated into the haze particles. The majority of $\mathrm{C}_{2} \mathrm{H}_{6}$ production occurs at lower altitudes than $600 \mathrm{~km}$ (Wilson \& Atreya 2004, 2009; Lavvas et al. 2008; Krasnopolsky 2009). However, changes in chemistry at higher altitudes due to different energy deposition with the use of HR cross sections is expected to cascade down to greater depths. Consequent changes in species concentrations may affect the formation rate and vertical profile of higher-order hydrocarbons and PAHs. As a result, the modeled peak $\mathrm{C}_{2} \mathrm{H}_{6}$ production and condensation altitudes may shift in the stratosphere.

Second, accurate representation of neutral vertical profiles is a key component in the proper assessment of Titan's coupled ion-neutral chemistry. Ion-molecule reactions play a role in the production and loss of various neutrals and important ions, such as $\mathrm{CH}_{3}^{+}, \mathrm{CH}_{5}^{+}, \mathrm{C}_{2} \mathrm{H}_{5}^{+}$, and $\mathrm{HCNH}^{+}$. It is noted that the majority of recent photochemical models overpredict the densities of the secondary ions $\mathrm{C}_{2} \mathrm{H}_{5}^{+}$and $\mathrm{HCNH}^{+}$that play a role in $\mathrm{HCN}$ and $\mathrm{C}_{2} \mathrm{H}_{6}$ production (e.g., Vuitton et al. 2006; Carrasco et al. 2007; de la Haye et al. 2008; Westlake et al. 2012) compared to INMS measurements. As the current work demonstrates, ion-molecule chemistry decreases with better resolution due to decreased ion densities. Approximately two times less $\mathrm{HCN}$ and $\mathrm{C}_{2} \mathrm{H}_{6}$ are produced through ion-molecule reactions with the use of HR cross sections between 600 and $1600 \mathrm{~km}$. Although the use of HR cross sections results in improved agreement between data and model, it is not enough to account for the discrepancy in these ion densities (see Mandt et al. 2012 for further discussion). Thus, the relative importance of ion-molecule and electron recombination processes for HCN production may still be overestimated.

There remain further questions on the disparity between models and measurements of minor species across Titan's atmosphere. A sensitivity study of the modeled vertical profiles of neutrals and ions to solar flux and diurnal variations is currently underway. We expect this will provide improved agreement on modeled and measured ion densities and, as a result, more accurate determination of the $\mathrm{HCN}$ vertical profile.

This work was supported by the NASA Outer Planet Research program NNH12ZDA001N.

\section{REFERENCES}

Adriani, A., Dinelli, B. M., López-Puertas, M., et al. 2011, Icar, 214, 584 Bell, J. M., Bougher, S. W., Waite, J. H., et al. 2010, JGR, 115, E14 Carrasco, N., Plessis, S., Dobrijevic, M., \& Pernot, P. 2008, Int. J. Chem. Kinet, 40, 699

Carrasco, N., Hébrard, E., Banaszkiewicz, M., Dobrijevic, M., \& Pernot, P. 2007, Icar, 192, 519

Coustenis, A., Nixon, C., Jennings, D. E., et al. 2014, in AAS/DPS 46, \#102.06

Coustenis, A., Jennings, D. E., Nixon, C. A., et al. 2010, Icar, 207, 461

Coustenis, A., Salama, A., Schulz, B., et al. 2003, Icar, 161, 383

Coustenis, A., \& Bézard, B. 1995, Icar, 115, 126

Cui, J., Yelle, R. V., Vuitton, et al. 2009, Icar, 200, 581

de la Haye, V., Waite, J. H., Cravens, J. H., et al. 2008, Icar, 197, 110

Fennelly, J. A., \& Torr, D. G. 1992, ADNDT, 51, 321

Gans, B., Peng, Z., Carrasco, N., et al. 2013, Icar, 223, 330

Gurwell, M. A. 2004, ApJL, 616, L7

Hidayat, T., Marten, A., Bézard, B., et al. 1997, Icar, 126, 170

Khare, B. N., Sagan, C., Ogino, H., et al. 1986, Icar, 68, 176

Kim, S. J., Geballe, T. R., Noll, K. S., \& Courtin, R. 2005, Icar, 173, 522

Koskinen, T. T., Yelle, R. V., Snowden, D. S., et al. 2011, Icar, 216, 507

Kostiuk, T., Livengood, T. A., Hewagama, T., et al. 2005, GeoRL, 32, 22205

Krasnopolsky, V. A. 2009, Icar, 201, 226

Kuiper, G. P. 1944, ApJ, 100, 378

Lara, L. M., Lellouch, E., López-Moreno, J. J., \& Rodrigo, R. 1996, JGR, 101, 23261 
Lavvas, P., Galand, M., Yelle, R. V., et al. 2011, Icar, 213, 233

Lavvas, P. P., Coustenis, A., \& Vardavas, I. M. 2008, P\&SS, 56, 67

Liang, M.-C., Heays, A. N., Lewis, B. R., Gibson, S. T., \& Yung, Y. L. 2007, ApJ, 664, 115

Livengood, T. A., Kostiuk, T., Sonnabend, G., et al. 2006, JGR, 111, 11

Livengood, T. A., Hewagama, T., Kostiuk, T., Fast, K., \& Goldstein, J. J. 2002, Icar, 157,249

Magee, B. A., Waite, J. H., Mandt, K. E., et al. 2009, P\&SS, 57, 1895

Mandt, K. E., Gell, D. A., Perry, M., et al. 2012, JGR, 117, 10006

Marten, A., Hidayat, T., Biraud, Y., \& Moreno, R. 2002, Icar, 158, 532

Niemann, H. B., Atreya, S. K., Demick, J. E., et al. 2010, JGR, 115, E12006

Richards, P. G., Woods, T. N., \& Peterson, W. K. 2006, AdSpR, 37, 315

Richards, P. G., Fennelly, J. A., \& Torr, D. G. 1994, JGR, 99, 8981
Shemansky, D. E., Stewart, A. I. F., West, R. A., et al. 2005, Sci, 308, 978

Tanguy, L., Bezard, B., Marten, A., et al. 1990, Icar, 85, 43

Toublanc, D., Parisot, J. P., Brillet, J., et al. 1995, Icar, 113, 2

Vervack, R. J., Sandel, B. R., \& Strobel, D. F. 2004, Icar, 170, 91

Vinatier, S., Bézard, B., Nixon, C. A., et al. 2009, Icar, 205, 559

Vinatier, S., Bézard, B., \& Nixon, C. A. 2007, Icar, 191, 712

Vuitton, V., Yelle, R. V., \& McEwan, M. J. 2007, Icar, 191, 722

Vuitton, V., Yelle, R. V., \& Anicich, V. G. 2006, ApJL, 647, L175

Westlake, J. H., Waite, J. H., Mandt, K. E., et al. 2012, JGR, 117, E01003

Wilson, E. H., \& Atreya, S. K. 2009, JPCA, 113, 11221

Wilson, E. H., \& Atreya, S. K. 2004, JGR, 109, 6002

Yelle, R. V. 1991, ApJ, 383, 380

Yelle, R. V., Cui, J., \& Müller-Wodarg, I. C. F. 2008, JGR, 113, 10003

Yung, Y. L., Allen, M., \& Pinto, J. P. 1984, ApJS, 55, 465 